Doi: 10.32481/djph.2021.09.009

\title{
Diagnosis and Treatment of Alzheimer's Disease:
}

\section{An Update}

Emily Bomasang-Layno, M.D., M.Sc. and Rachel Bronsther, M.D.

Department of Psychiatry, ChristianaCare

\section{Introduction}

Alzheimer's Disease (AD) exerts a significant worldwide impact. An estimated 44 million individuals currently live with this Major Neurocognitive Disorder. There are about 6.2 million Americans with AD dementia today and AD kills more people than breast cancer and prostate cancer combined. The National Institute on Aging estimates that the prevalence of AD doubles every five years beyond the age of 65 and as the population ages, a greater proportion of the population is affected. AD will cost the United States over $\$ 355$ billion in 2021, rising to over $\$ 1.5$ trillion by $2050^{1}$ imposing a significant economic burden. Early diagnosis and treatment of neurocognitive disorders are critical in determining treatment approaches and shaping policy to prepare for the deluge of cases to come. This review describes current diagnostic approaches and treatment advances for AD.

\section{Current Diagnostic Strategies}

The evaluation of a person with suspected memory impairment includes a comprehensive set of assessments aimed at characterizing the etiology of cognitive decline and identifying treatable pathologies. These assessments include a detailed medical history, physical and mental status examinations, basic labs, and neuroimaging studies. Additional tools may also include neuropsychological testing and advanced brain imaging techniques. Once reversible causes have been ruled out, clues for specific causes of major neurocognitive disorder are sought. A history of multiple strokes, for example, may point towards a diagnosis of vascular dementia. A history of head trauma may suggest traumatic encephalopathy. A history of prolonged alcohol use disorder may support the diagnosis of an alcohol-related dementia. In adults over 60, the most frequent cause of progressive cognitive decline is $\mathrm{AD} .^{2}$

\section{Emerging Diagnostics}

Finding earlier and more definitive ways to diagnose AD has been the subject of significant amounts of research, and testing advances have been seen in the last decade with expanded use of positron emission tomography (PET) and magnetic resonance imaging (MRI), as well as in the identification of biomarkers in cerebrospinal fluid (CSF) and more recently serum. While limited, some of these diagnostic advances are available to the public, though typically at a high price.

A high-level overview of emerging diagnostic strategies can be found below.

\section{Volumetric Data}

In simple terms, volume changes in specific brain regions can predict the likelihood of progression from mild cognitive impairment (MCI) to AD. These volume assessments can be done by radiologists or with the help of FDA-approved MRI volumetric data software packages 
such as Neuroquant and Neuoreader. Hippocampal volume changes in particular are regarded as an important AD biomarker. ${ }^{3}$ Because of limited sensitivity of this measure in diagnosing $\mathrm{AD}$, however, MRI studies are regarded as a contributor to the diagnostic process but not sufficient in themselves for determining a diagnosis. ${ }^{4}$

\section{Diffusion Tensor Imaging}

Diffusion Tensor Imaging (DTI) is an advanced neuroimaging technique that uses the diffusion properties of water molecules to generate magnetic resonance images that correspond to changes in macroscopic axonal organization. This technique can be used to evaluate the structure of vertical cellular micro-circuits, termed "minicolumns." Previous studies have demonstrated that minicolumns are known to be altered in a somewhat predictable and progressive manner during aging, MCI, and AD. ${ }^{5}$ Additionally, pathologic changes of cortex columnar architecture are associated with increased plaque load and cognitive decline. ${ }^{6}$ With the aid of proprietary software, DTI can be measured and used as a marker of neurodegeneration.

\section{PET Scan}

Pathologic species of two proteins, amyloid- $\beta(A \beta)$ and hyperphosphorylated tau accumulate in the brains of persons with AD. PET scans are able to assess for both proteins and serve as a reliable biomarker. Amyloid accumulation precedes clinically significant cognitive changes and tau accumulation progresses in step with cognitive decline, suggesting the value of PET scans for diagnosis and measurement of disease progression. ${ }^{7}$

\section{CSF and Blood Tests}

Cerebrospinal fluid (CSF), accessible through lumbar puncture, surrounds the brain. Changes in the levels of $A \beta$ and tau proteins in the CSF develop decades before the onset of clinically significant $\mathrm{AD}{ }^{8}$ Among the tests of CSF developed during recent decades, the most prominent are CSF $A \beta 42: A \beta 40$ ratio and the CSF tau phosphorylated at threonine 181 (P-tau181). CSF Ptau217, measurable in the peripheral circulation, is hoped to provide a biomarker with very high sensitivity and specificity. ${ }^{9}$

Because blood is more easily accessed than CSF, C2N Diagnostics in St. Louis, Missouri has developed and released a blood test called PrecivityAD which is available in most of the U.S. and to the European Union. The test uses mass spectrometry to detect specific species of betaamyloid in serum which are lower in AD. The test is not presently covered by insurance, representing a significant cost that may be defrayed for eligible individuals through a financial assistance program. The test is not a stand-alone diagnostic tool; rather the results are a probability score and are intended to be interpreted in concert with other testing means. ${ }^{10}$ Additionally, research on plasma $A \beta 42: A \beta 40$ ratio and P-tau181 suggests potential value. ${ }^{11,12}$

\section{Implications of New Diagnostic Strategies: Risks vs. Benefits}

\section{Benefits}

Although some people express the wish not to know, almost $90 \%$ of people surveyed in a large US study expressed a wish to know their diagnosis. Sixty-five percent of respondents said that even if they were asymptomatic they would be likely or somewhat likely to accept a medical test to assess for AD. ${ }^{13}$ Early detection offers the benefits of earlier access to medications, inclusion 
in clinical trials, the opportunity for lifestyle modification, and knowledge useful to families in preparing for the future while the affected individual remains able to participate actively in decision-making.

\section{Risks}

Early detection and disclosure, however, also carry risks. The mental health effects of receiving a diagnosis are known to be significant not only for patients but also for families. Multiple studies have documented a small increase in death by suicide in those with dementia, most prominently during the first three months after a diagnosis was made. ${ }^{14}$ This suggests the need for increased mental health support and monitoring particularly in the early months after a diagnosis is given, as well as the importance of educating family about suicide risk. As treatment options for early stage dementia increase, the benefits and risks of early diagnostic assessment will become a matter of great significance.

\section{Current Therapeutic Strategies and Options}

Several mechanisms have been proposed to account for the pathology of AD, and current treatments are counteract these mechanisms. The most widely accepted disease models are the amyloid cascade hypothesis, the tau hypothesis, the cholinergic hypothesis, and the excitotoxicity hypothesis.

Our current AD medications were developed to address the cholinergic deficit that occurs early in AD. The selective loss of cholinergic neurons, an early pathologic finding in AD, results in a profound reduction in the neurotransmitter acetylcholine, which affects learning and memory neuronal circuitry. Facilitating cholinergic transmission was therefore an early approach to AD treatment which resulted in several palliative medications still in use. ${ }^{15-17}$

\section{Cholinesterase Inhibitors}

The primary action of the cholinesterase inhibitors is the reversible inhibition of cholinesterase, the enzyme which breaks down acetylcholine in brain synapses, thereby prolonging the effect of the diminished level of brain acetylcholine. ${ }^{18,19}$ Three cholinesterase inhibitors are currently used: donepezil, rivastigmine, and galantamine. Meta-analyses have shown that these agents delay decline in cognitive function, slow the decline in global clinical rating, and may delay the decline of activities of daily living (ADL) and emergence of adverse behaviors, as much as 6 to 12 months on average. ${ }^{20,21}$ Significant side effects include gastrointestinal symptoms, dizziness, vertigo, fatigue, insomnia, hallucinations, bradycardia, syncope, and muscle cramps. ${ }^{15}$

Donepezil is a reversible non-competitive acetylcholinesterase inhibitor shown to affect cognitive function, activities of daily living, and global clinical status. Benefits for the $10 \mathrm{mg}$ dose appear marginally larger than for the $5 \mathrm{mg}$ dose. A larger 23-mg dose form is available, with disputed clinical advantages. ${ }^{20}$

Rivastigmine is a pseudo-irreversible inhibitor of acetylcholinesterase and butyrylcholinesterase and acts by binding to two active sites of acetylcholinesterase. It is called pseudo-irreversible because it dissociates slower than acetylcholinesterase. ${ }^{20}$ Adverse effects of the oral preparation are significant, but the transdermal form is more tolerable for many patients, although it can cause dermatologic reactions. $^{22,23}$ 
Galantamine is a reversible competitive acetylcholinesterase inhibitor and modulator of nicotinic acetylcholine receptors. ${ }^{15}$ Theoretically, this agent will have greater effect in areas of the brain with low levels of acetylcholine. ${ }^{24}$ Its effects are similar to those of the other cholinesterase inhibitors. $^{24}$

\section{NMDA Receptor Antagonist}

Overstimulation of glutamatergic activity in the brain results in an excitotoxic overload of calcium flux into neurons through N-methyl-D-aspartate (NMDA) receptor ion channels. ${ }^{25,26}$ Excitotoxicity leads to a gradual loss of synaptic function and eventual neurodegeneration, correlating with the progressive decline in cognition and the pathological anatomy seen in AD. ${ }^{27}$ The NMDA receptor plays a critical role in glutamate synaptic transmission and in synaptic plasticity, thought to underlie learning and memory. ${ }^{28}$ Memantine, a low-affinity NMDA receptor antagonist, modulates NMDA receptors to reduce glutamate-induced excitotoxicity and is thought to palliate cognitive decline associated with $\mathrm{AD}$ in this way. ${ }^{27,28}$ Memantine is FDAindicated for moderate to severe AD. ${ }^{29}$ It has been shown to improve activities of daily living scores, global function assessment scores, and stage of dementia assessment scores. ${ }^{30,31}$ It has also been suggested that it can be efficacious in reducing delusions, agitation/aggression, disinhibition, and diurnal rhythm disturbances. ${ }^{32}$ Although benefit is clear, its magnitude is modest. ${ }^{31}$ It is available as immediate and extended-release formulations, and as part of a combination pill with donepezil. ${ }^{15}$ The combination of a cholinesterase inhibitor with memantine appears to have synergistic benefits so it is a standard practice in the treatment of moderate to severe $\mathrm{AD} .^{33}$

\section{Emerging Treatments}

The search for disease-modifying AD therapies has led to the development of medications which target the pathologic forms of amyloid beta $(\mathrm{A} \beta)$ protein and tau protein associated with this disease. ${ }^{34}$ The amyloid cascade hypothesis proposes that toxic forms of $A \beta$ protein leads to neuronal death and synaptic dysfunction. A $\beta$ pathology is an early finding in the disease. ${ }^{34,35}$ The tau pathology has been shown to correlate more specifically with the progression of cognitive impairment. ${ }^{36,37}$

\section{Targeting Amyloid Pathology}

The neurodegenerative effects of AD are attributed in part to the effects of beta amyloid and hyperphosphorylated tau, though newer theories raise additional possibilities. Amyloid plaques and tau-containing neurofibrillary tangles remain necessary for a pathological diagnosis of AD. ${ }^{38}$ Several familial forms of AD have been linked to genetic mutations which alter the production of amyloid. CSF biomarker studies have also shown that A $\beta 42$ peptides decline one to two decades prior to onset of symptoms in AD. ${ }^{39}$ Although insoluble aggregates and soluble dimers of amyloid have been demonstrated to cause synaptic toxicity, the soluble aggregates are considered to correlate better with symptoms of AD and disease severity. ${ }^{40}$

Therapeutic agents have been developed to reduce different forms of pathologic $A \beta$, interrupt $A \beta$ aggregation, or increase A $\beta$ clearance from the CNS. Many tested agents, however, have failed to demonstrate efficacy and some have even caused worsening of cognitive or physical symptoms, raising questions about the amyloid hypothesis. ${ }^{41}$ Newer research techniques seek to 
improve drug evaluation by assuring that adequate measures are used and appropriate subjects enrolled in clinical trials. ${ }^{42}$

\section{Passive Immunotherapeutics}

Following the early failure of a vaccine intended to develop a beneficial immune response in persons with $\mathrm{AD}$, researchers developed passive immunotherapeutic agents: monoclonal antibody solutions created in biological systems for infusion into human subjects. ${ }^{43}$ The objective is to reduce peripheral and central effects of $A \beta 42 .{ }^{44}$ Several passive immunotherapeutic agents have failed clinical trials, but others remain in testing.

Aducanumab (BIIB037) is a human anti-A $\beta$ monoclonal antibody that selectively targets aggregated forms of $\mathrm{A} \beta$, including soluble oligomers and insoluble fibrils. Given as an infusion, aducanumab enters the central nervous system and decreases $A \beta$ in prodromal or mild AD with A $\beta$ PET-confirmed pathology, in a time and dose-dependent manner. Significant plaque reduction has been demonstrated. The main safety finding has been dose-related amyloid-related imaging abnormalities - edema/effusion (ARIA-E) which are more common among Apo-E4 carriers. In subjects who received the highest dose of $10 \mathrm{mg} / \mathrm{kg}$, researchers reported a significant decline in the progression of cognitive impairment (on the CDR-Sum of Boxes). ${ }^{45}$ In June of 2021, aducanumab was approved by the FDA for treatment of AD with the stipulation that a phase IV trial carefully assess its efficacy and safety. Subsequently, amidst some controversy about the accelerated approval process which occurred despite limited evidence of treatment benefit, the FDA revised the medication's indication to target its use toward AD-related mild cognitive impairment or mild dementia.

Lecanemab (BAN2401) is a humanized IgG1 version of a mouse monoclonal antibody which selectively binds to large soluble $A \beta$ protofibrils. Lecanemab has been shown to slow cognitive decline, increase CSF levels of $A \beta$ (which drop in AD), and reduce total tau levels ${ }^{46}$ but further validation of current findings is needed to address concerns about the methodology of the initial studies. Three clinical trials are currently in progress, looking at efficacy and safety among early AD subjects (NCT03887455); efficacy and safety among early preclinical and preclinical AD subjects with early and intermediate amyloid (NCT04468659); and safety, efficacy, and tolerability of different dose levels among early AD patients (NCT01767311).

Donanemab (LY3002813) is an immunoglobulin directed towards a molecular target present only in brain amyloid plaques. In a phase II trial among early AD subjects, there was some improvement in composite cognition scores and ability to do activities of daily living (ADLs), but secondary outcomes did not show a significant difference. ARIA-E were observed but were noted to be asymptomatic. ${ }^{47} \mathrm{~A}$ dose escalation study of single and multiple doses explored safety and tolerability and showed $40-50 \%$ amyloid reduction and $90 \%$ of subjects developed drug antibodies at three months after a single dose. ${ }^{48}$

Gantenerumab, an additional monoclonal antibody in testing, has a 20 -fold higher affinity for $\mathrm{A} \beta$ oligomers than monomers. ${ }^{49}$ The earlier phase II trial was terminated for futility but there were dose-dependent effects observed indicating that higher doses may be necessary for efficacy. ${ }^{50} \mathrm{An}$ analysis of a PET sub-study suggests that at higher doses, there is a robust reduction of amyloid at two years. ${ }^{51}$ There are currently ongoing trials evaluating pharmacodynamics of subcutaneous administration (NCT04592341); safety and tolerability of long-term administration (NCT04339413); safety and efficacy among early AD subjects (NCT03443973, NCT03444870); 
and safety, tolerability, biomarker, and cognitive efficacy among genetic early onset AD (NCT01760005).

Crenezumab is a monoclonal antibody which binds to monomers and aggregated forms of A $\beta$ with a 10 -fold higher affinity for oligomers. ${ }^{52}$ Earlier clinical trials did not meet clinical endpoints but there was note of a reduction in clinical decline in the higher dose group, as with gantenerumab. ${ }^{53}$ Ongoing trials currently are evaluating crenezumab and its effect on tau burden among presenelin mutation carriers and noncarriers (NCT03977584) and efficacy among preclinical AD (NCT01998841).

\section{BACE Inhibitors}

$\beta$-site amyloid precursor protein cleaving enzyme (BACE) is an enzyme which performs the initial step in $\mathrm{A} \beta$ formation. ${ }^{41}$ Several agents have been developed to block BACE activity in order to reduce $A \beta$ accumulation.

Clinical failures of BACE inhibitors among persons with mild to moderate AD and prodromal AD have occurred with lanabecestat (AZD3293, LY3314814), atabecestat (JNJ-54861911), and verbecestat (MK8931). Elenbecestat (CNP520) was the last remaining BACE inhibitor evaluated to potentially slow down the onset and progression of clinical symptoms associated with AD (NCT02565511). The trial was discontinued for safety concerns. ${ }^{54}$

BACE inhibitors are successful in inhibiting $A \beta$ formation but they have not been shown to produce cognitive, clinical, or functional benefit in large randomized controlled trials (RCT). Indeed, several BACE inhibitors were found to be poorly tolerated and some of them failed also in patients with prodromal AD. To some investigators, the failure of BACE inhibitors casts doubt on the value of blocking the formation of toxic $\mathrm{A} \beta$ in persons with $\mathrm{AD}{ }^{55}$

\section{Anti-Aggregation Agents}

Another approach to interfering with the amyloid cascade is to block the aggregation of $A \beta$ into oligomers and fibrils into amyloid plaques which may trigger the synaptic dysfunction and neuronal loss in $\mathrm{AD}$. The soluble oligomers are considered the pathogenic form of $\mathrm{A} \beta$ associated with neurodegeneration. ${ }^{56}$

Scyllo-Inositol (ELND005) has been shown to neutralize toxic effects of A $\beta$ oligomers, including amelioration of oligomer-induced synaptic loss. ${ }^{57}$ It is also thought to directly affect both A $\beta$ clearance and myo-inositol regulation to improve cognitive function. ${ }^{58}$ Its efficacy outcomes in mild to moderate $\mathrm{AD}$, however, have not been found to be significant. ${ }^{59}$ No ongoing trials are addressing its effect on earlier AD stages.

ALZ-801 is an improved prodrug of tramiprosate thought to inhibit the formation of amyloid oligomers without plaque interaction. ${ }^{60,61}$ It selectively blocks the formation of $A \beta$ oligomers with some clinical efficacy among high risk APOE carriers at a high dose and a dose dependent preservation of hippocampal volume. This is an oral agent which has been shown to have adequate CNS penetration. ${ }^{60,62}$ Ongoing trials are looking into the effect of ALZ-801 on biomarkers (NCT04693520) and efficacy and safety (NCT04770220), both in APOE carriers. 


\section{Tau Directed Therapies}

The lack of clear efficacy of amyloid-based therapeutics has led investigators to explore other upstream pathologic processes involving other targets. ${ }^{46} \mathrm{Tau}$, a microtubule binding protein which forms neurofibrillary tangles (NFTs), is another histopathologic hallmark which characterizes AD. The accumulation of tau has been found to correlate more closely with severity of dementia than does amyloid load. There is evidence that $A \beta$ accumulation can exacerbate tau pathology and vice versa. ${ }^{63}$ Tau protein has also been found to at least partially mediate some of the toxic effects of $\mathrm{A} \beta$ leading to synapse loss, dendritic simplification, and eventual cell death in AD. ${ }^{34}$ Initial approaches for tau-based therapies have focused on inhibition of kinases or tau aggregation or stabilization of microtubules. Most of these studies have been discontinued due to toxicity or lack of efficacy. ${ }^{64}$ Current trials are focused on tau immunotherapies. Post-translational modifications and consequent loss of microtubule binding and tau misfolding lead to elevated levels of tau in the cytosol, making these processes viable targets. $^{34,64}$ Other significant targets include cytoskeletal disruption and impairments in protein degradation mechanisms. ${ }^{64}$

\section{Inhibition of Tau Aggregation}

Methylene blue (MB) is a long established medication with broad utility in many conditions due to its role in promoting mitochondrial activity as well as mitigating neuroinflammation. ${ }^{65}$ In animal models, $\mathrm{MB}$ has been shown to reduce $A \beta$ levels and improved learning and memory thought to be mediated by an increase in $A \beta$ clearance. ${ }^{66}$ It has been found to reverse tau aggregation ${ }^{67}$ and to promote clearance of tau filaments by inducing autophagy. ${ }^{64}$ Although some efficacy was noted in improving cognition and reducing tau pathology in animal studies, it has not demonstrated significant benefits in human trials. This has been attributed to MB reducing the number of tau fibrils but increasing the number of granular tau oligomers, which are thought to be essential for neuronal death. ${ }^{6}$

Curcumin is a natural plant product derived from turmeric root, with antioxidant and antiinflammatory properties. It directly binds to $\beta$-pleated sheets of proteins and prevents aggregation. ${ }^{69}$ Like $\mathrm{MB}$, it has also been shown in animal studies to reduce tau and $\mathrm{A} \beta$ pathology and ameliorate cognitive deficits. ${ }^{64}$ Previous trials have not shown any significant cognitive effects. ${ }^{70}$ A recent trial involving a small population showed only modest results (NCT01383161). The clinical development of curcumin as a therapeutic agent has been hindered by concern about bioavailability, poor water solubility at neutral or acidic $\mathrm{pH}$, instability at basic $\mathrm{pH}$, and rapid intestinal and first pass glucuronidation. ${ }^{69}$

\section{Post Translational Modifications}

Protein phosphatase 2A (PP2A) is a protein that regulates signaling pathways. Sodium selenate is an antitumor agent which has been found to be a potent PP2A activator and reduces phosphoprylation of tau in animal studies in $\mathrm{TBI}^{71}$ and $\mathrm{AD} .{ }^{72}$ In a phase IIa trial, ${ }^{73}$ it was found to be safe and well-tolerated but there were no subsequent efficacy trials. A recent trial utilized sodium selenate as an oral supplement to potentially slow down neurodegeneration, based on the hypothesis that insufficient selenium supply to antioxidant enzymes may contribute to AD pathophysiology. ${ }^{74}$ 
CDK5 inhibitors (flavopiridol and roscovitin) were developed primarily in oncology to prevent cell death. They compete with ATP for binding with CDK5, resulting in reduced activation of this kinase. ${ }^{75}$ They have not been tested for neurodegenerative diseases although it has been thought that cell cycle progression and/or mitosis may be valid targets for AD. ${ }^{76}$

Glycogen synthase kinase (GSK) $3 \beta$ is highly expressed in the brain and has been implicated in tau phosphorylation. It is considered an important drug target due to its high specificity as a substrate. ${ }^{77}$ Tideglusib is an irreversible GSK3$\beta$ that does not compete with ATP. A phase II trial on mild AD subjects, however, showed tideglusib to have no clinical benefit. ${ }^{78}$ An additional phase II trial showed no benefit to subjects with progressive supranuclear palsy (PSP). Lithium is another inhibitor of GSK3. Studies among patients with MCI and AD have been limited, but a reduction in phospho-tau levels were noted and one study showed stabilization of cognitive symptoms. In a meta-analysis of 5 RCTs on GSK 3 inhibitors, however (two trials on Tideglusib and three trials on lithium), GSK3 inhibitors were deemed ineffective in treating MCI and AD as the studies were found to be too small. ${ }^{79}$

\section{Microtubule Stabilization}

Compounds that stabilize microtubules may have therapeutic potential as the disruption of microtubule-based transport mechanisms contributes to synaptic degeneration. ${ }^{80}$

Epithilone D (BMS-241027) is a small molecule able to penetrate the blood brain barrier. It was found to increase microtubule numbers and reduce the number of axons in animal studies. ${ }^{34}$ There was also note of improved cognition and reduced tau pathology in mouse models but the phase I clinical trial was discontinued in 2013 (NT 01492374).

TPI 287 (Abeotaxane) is another microtubule stabilizing compound which was initially found to reduce hyperphosphorylated tau in the brain and to improve performance in animal models. It was subsequently trialed in patients with $\mathrm{AD}$, progressive supranuclear palsy, and corticobasal syndrome. Severe hypersensitivity reactions, however, were observed in AD patients and clinical worsening and biomarker changes were seen in PSP and corticobasal syndrome. ${ }^{81}$

Davenutide (NAPVSIPQ) is an 8-amino acid peptide derived from activity-dependent neuroprotective protein (ADNP). ADNP deficiency is thought to lead to tauopathies. ${ }^{34}$ In animal models, davenutide was found to play a positive role in attenuating A $\beta 1-42$-induced impairments in spatial memory and synaptic plasticity. ${ }^{82}$ It is thought to stabilize microtubules and reduce hyperphosphorylated tau levels. ${ }^{83}$ In a phase I trial, it was found to be well tolerated given intranasally among patients with MCI. Although there was note of potential efficacy in two tests of memory and attention, the study failed to detect a statistically significant difference on composite cognitive memory scores. ${ }^{84}$

\section{Tau Immunization Approaches}

Active and passive immunization against phospho-tau peptides have the potential to modulate tau pathology. Antibodies pass through the blood brain barrier and enter the brain. ${ }^{34}$

One candidate active vaccine is AADvac1 which targets nonphsophorylated tau. In its phase I trial, patients were given 3 doses of the vaccine. Almost all developed an IgG immune response. The most common adverse effect was injection site reactions. There were no cases of meningoencephalitis or vasogenic edema after administration. ${ }^{85} \mathrm{~A}$ follow-up study was done on the same population and given three more doses plus two boosters with the primary objective 
being the determination of long-term safety. The most common adverse event was again local injection site reaction. Again, no cases of meningoencephalitis or vasogenic edema were observed. New micro-hemorrhages were observed in one Apo E4 homozygote. IgG titers did regress over time indicating the need for more frequent boosters. A tendency towards slower atrophy on MRI was observed and there seems to be a slower decline on cognitive assessment in those with higher titers. ${ }^{86}$

ACI-35 is another active vaccine that targets phosphorylated tau. ${ }^{87}$ In animal studies, there was note of reduction in soluble and insoluble tau. The vaccine also did not induce marked CNS inflammation despite the multiple epitopes. ${ }^{75,88}$ A phase Ib-IIa trial is currently ongoing to determine safety, tolerability, and immunogenicity. It is expected to complete by 2023 (NCT04445831).

\section{Passive Immunization}

Passive immunization potentially provides a possible solution to concerns about immunologic side effects with active immunization. There is greater specificity for the target epitope and the effects of immunization are likely to be transient. ${ }^{75}$ Anti-tau antibodies have been shown to enter neurons and bind to a cytosolic receptor which eventually leads to proteosomal degradation of the complex and inhibition of intracellular tau aggregation. ${ }^{89-91}$

RG7345 (RO6926496) is an antibody that recognizes tau phosphorylated at Ser422. Tau phosphorylated at this site is considered pathological. ${ }^{92}$ It has been shown to enter neurons and reduce tau pathology, but this trial was discontinued by Roche likely due to some pharmacokinetic issues (NCT02281786). No apparent safety or efficacy concerns. ${ }^{75}$

Gosuranemab (BIIB092) is an IgG4 monoclonal that recognizes a site in the N-terminal region. It was found safe and well-tolerated with no adverse effects in the low and moderate dosage arms. Unbound N-terminal tau in the CSF was reduced but AD biomarkers were not reduced..$^{93,94}$ There is currently a phase II trial for those with MCI and mild AD assessing safety and tolerability plus immunogenicity and efficacy of multiple doses in slowing cognitive and functional impairment (NTC 03352557). Expected completion of the study is in 2024.

Tilavonemab (ABBV-8E12, C2N-8E12) is an IgG4 antibody intended to work extracellularly. In vitro, this blocks uptake and inhibits seeded tau aggregation. ${ }^{63}$ No adverse reactions were reported among PSP patients in phase I. Phase II trials included both PSP patients and AD patients. The trials for PSP were discontinued. The trials for AD patients, however, are still ongoing with the extension study expected to conclude July 2021 (NCT02880956, NCT03712787).

Zagotenemab (LY3303560) is a humanized version of the IgG1 antibody MC-1 with its primary epitope located in the N-terminal region. ${ }^{63}$ The initial phase I trial evaluated safety, tolerability, and pharmacokinetics in healthy individuals (NCT02754830) and among those with mild to moderate AD (NCT 03019536). A phase II trial is underway evaluating efficacy among early symptomatic AD patients (NCT03518073). Study completion is estimated to be in October 2021.

Semorinemab (RO7105705, MTAU9937A) is an antibody designed to bind and intercept tau in the extracellular brain, blocking cell-to-cell spread. ${ }^{63}$ Initial phase I results showed no doselimiting toxicities and no serious adverse effects. The antibody was also detected in CSF. ${ }^{95,96}$ The phase II trial on prodromal to mild AD was completed January 2021 and primary endpoints were 
safety measures and CDR-Sum of Boxes (NCT3289143). The phase II trial on moderate AD is still ongoing at this time (NCT03828747).

BIIB076 (NI-105, 6C5 hulgG1/I) is a human IgG1 recombinant monoclonal antibody. Intravenous and subcutaneous forms were assessed up to 26 times highest predicted dose. Drug levels were measured in the serum and tau levels were measured in the CSF. No adverse effects noted. ${ }^{92}$ The phase I trial on ascending doses given to healthy volunteers and AD patients monitored adverse events as well as pharmacokinetics (NCT03056729). This study was completed in March 2020 but no results have been posted or published.

JNJ-63733657 is an IgG1 antibody with affinity for the paired helical filament. ${ }^{63}$ It recognizes an epitope in the mid region of tau. The phase I trial of ascending doses in healthy participants found this antibody to be generally safe and well-tolerated (NCT03689153). A second phase I ascending dose study was completed in December 2019 (NCT03375697) with no results posted yet. A phase II trial on efficacy and safety in early AD is currently ongoing and expected to complete by March 2025 (NCT04619420).

Bepranemab (UCB0107) is likely an IgG4 (Alzforum.org 2019b). It also binds to the mid-region of tau, like JNJ-63733657. ${ }^{92}$ Two phase I clinical trials were completed in 2018 and 2019 (NCT03464227, NCT 03605082). There are two other phase I trials involving safety and tolerability in PSP patients. The phase II study involving AD patients is not yet recruiting at this time (NCT04867616).

\section{Treatment of Noncognitive Symptoms of Dementia}

Noncognitive symptoms of dementia (NCSD) are symptoms that contribute significantly to functional decline, caregiver burden, and eventually, the decision for institutionalization. ${ }^{97}$ Early treatment, therefore, is essential. These symptoms present intermittently or persistently. The most prevalent and stable is apathy. Other symptoms include depression, anxiety, irritability, and psychosis. The four key symptoms of wandering, aggression/agitation, delusions, and irritability have been found to be associated with more severe illness. ${ }^{98}$ Nonpharmacologic approaches are designated as the first line approach for treatment. Pharmacological interventions have been prescribed as well and are often seen as more expedient, though with variable benefit. Their use is complicated by adverse effects, dose-dependent increased mortality, and limited supporting evidence. ${ }^{99-101}$ The concern for risks associated particularly with antipsychotic use has resulted in boxed warnings by the FDA for atypical and conventional antipsychotics. ${ }^{99}$ Furthermore, none of these pharmacologic agents have been indicated for this use by the FDA so their use is offlabel. The American Psychiatric Association's (APA) guideline on antipsychotic use to treat agitation or psychosis in dementia recommends that antipsychotics be used when symptoms of agitation or psychosis are severe, dangerous, or cause significant distress to the patient, titrating doses only to the minimum effective dose, and to taper and withdraw once an adequate response is achieved. ${ }^{102}$ Ultimately, among the antipsychotics, there is no single agent that is able to provide both efficacy and safety emphasizing the need to individualize treatment based on a careful balance of benefits and adverse effects. ${ }^{103}$

Serotonergic antidepressants offer a more promising pharmacologic approach to the treatment of NCSD. Citalopram, a selective serotonin reuptake inhibitor (SSRI), has been shown to have some efficacy for agitation in dementia. ${ }^{104}$ In a placebo controlled, double blind RCT, citalopram was found to meaningfully reduce agitation and caregiver distress. Some associated cognitive 
decline and cardiac side effects (QTc prolongation), however, hamper its long-term use. ${ }^{105,106}$ Results suggest that citalopram needs to be given at least nine weeks to allow enough time for a full response. ${ }^{107}$ The evidence for its use for this indication, nevertheless, remains compelling, and potentially could be a class effect for all SSRIs. ${ }^{108,109}$

Some additional novel and/or repositioned agents are being studied as treatments for agitation in dementia.99 Four will be discussed here.

Dextromethorphan is a sigma-1 receptor agonist which has some mood-modulating properties. ${ }^{110}$ It is also a low affinity NMDA antagonist, a serotonin and norepinephrine reuptake inhibitor, a histamine $\mathrm{H} 1$ receptor agonist, and a neuronal nicotinic alpha-3 beta-4 receptor antagonist. ${ }^{99,111}$ Quinidine and deuteration appear to prolong dextromethorphan's plasma half-life, reduce first pass metabolism, and facilitate brain penetration. ${ }^{12}$ Deuterated (d6)-dextromethorphan/quinidine (AVP-786) is currently being evaluated as a treatment for agitation in people with AD. ${ }^{113}$ Two phase III trials evaluating efficacy, safety, and tolerability have been completed, NCT02442765 (February 2020) and NCT02442778 (August 2020). The two trials reportedly showed mixed findings and failed to confirm the anti-agitation effect, probably due to differences in study design. ${ }^{113,114}$ Four ongoing trials are currently recruiting subjects (NCT04464564, NCT04408755, NCT03393520, NCT02446132).

Cannabinoids like tetrahydrocannabinol (THC) are agonists at cannabinoid receptors 1 and 2. Cannabinoid receptor activity has behavioral effects and modulates of neuroinflammation and oxidative stress, so these receptors are a potential drug target. ${ }^{115}$ Nabilone, a synthetic oral THC which is a partial agonist at CB1/2 receptors, is thought to potentially have some efficacy for agitation in moderate to severe $\mathrm{AD} .{ }^{116}$ In a recent RCT evaluating nabilone efficacy and safety, it was found to be effective for agitation, although with some dose-related sedation. Observational studies have also shown promising results, particularly in cases with refractory symptoms. ${ }^{117}$ Two of three recent meta-analyses were unable to show conclusive results for cannabinoid efficacy in the treatment of agitation or aggression. ${ }^{118,119}$ The most recent meta-analysis, however, was able to show significant improvement in different NPS instruments and efficacy was associated with baseline dementia severity and dose. ${ }^{120}$

Brexpiprazole is a partial receptor agonist (D3, D2, 5-HT1A) and receptor antagonist (5HT2A, alpha1B/2C) which has been shown in phase II trials to be effective for agitation in patients with AD with improved safety profile compared with other second generation antipsychotics. ${ }^{121,122}$ Of note, brexpiprazole on a slow titration schedule, had higher efficacy and tolerability. There are several ongoing phase III trials (NCT03594123, NCT03724942, NCT03548584, NCT03620981) to evaluate long term use, safety, efficacy.

Prazosin is a centrally acting alpha 1 receptor antagonist indicated for hypertension and symptoms of benign prostatic hypertrophy. It readily crosses the blood brain barrier and in a small double-blind trial, it has shown efficacy for agitation among patients with moderate AD using a flexible dosing titration up to a maximum of $6 \mathrm{mg}$ TDD. It was also well tolerated. ${ }^{123} \mathrm{~A}$ completed but unpublished second trial looked into the efficacy of a fixed dose of $4 \mathrm{mg}$ twice daily given for a longer period of study (NCT01126099). A phase III trial is ongoing to evaluate efficacy and dose titration (NCT03710642).

Mirtazapine (NCT03031184, completed 06/2020) and lithium (NCT02129348, completed 01/2020) have also been evaluated for agitation in AD but results have yet to be published. Escitalopram is being reevaluated for agitation as well (NCT03108846, ongoing recruitment). ${ }^{99}$ 


\section{Public Health Implications}

We may be standing at the brink of a new era of AD diagnosis and treatment, a development which will have significant public health implications. If early detection becomes a reality, the detected individuals will burden an already stressed system by new care needs. Resources may need to be directed at increasing public awareness of the health implications of dementia. Dissemination of information about the effectiveness of treatments will be needed as well as work to remove the stigma associated with mental health disorders and the stigma of being treated for them. Furthermore, overall access to mental health services needs to be improved. ${ }^{124,125}$

The current advances should inspire hope, however, that many cases of dementia can be delayed or prevented as a result of earlier detection, lifestyle modifications, and new treatment approaches. We are on the verge of a paradigm shift in the way we approach AD.

\section{References}

1. Alzheimer's Association. (2021, March). 2021 Alzheimer's disease facts and figures. Alzheimers Dement, 17(3), 327-406. PubMed https://doi.org/10.1002/alz.12328

2. Neugroschl, J., \& Wang, S. (2011, July-August). Alzheimer's disease: Diagnosis and treatment across the spectrum of disease severity. The Mount Sinai Journal of Medicine, New York, 78(4), 596-612. PubMed https://doi.org/10.1002/msj.20279

3. Tanpitukpongse, T. P., Mazurowski, M. A., Ikhena, J., \& Petrella, J. R., \& the Alzheimer's Disease Neuroimaging Initiative. (2017, March). Predictive utility of marketed volumetric software tools in subjects at risk for Alzheimer disease: Do regions outside the hippocampus matter? AJNR. American Journal of Neuroradiology, 38(3), 546-552. PubMed https://doi.org/10.3174/ajnr.A5061

4. Lombardi, G., Crescioli, G., Cavedo, E., Lucenteforte, E., Casazza, G., Bellatorre, A.-G., . . . Filippini, G. (2020, March 2). Structural magnetic resonance imaging for the early diagnosis of dementia due to Alzheimer's disease in people with mild cognitive impairment. Cochrane Database Syst Rev, 3(3), CD009628. PubMed https://doi.org/10.1002/14651858.CD009628.pub2

5. Chance, S. A., Clover, L., Cousijn, H., Currah, L., Pettingill, R., \& Esiri, M. M. (2011, August). Microanatomical correlates of cognitive ability and decline: Normal ageing, MCI, and Alzheimer's disease. Cereb Cortex, 21(8), 1870-1878. PubMed https://doi.org/10.1093/cercor/bhq264

6. van Veluw, S. J., Sawyer, E. K., Clover, L., Cousijn, H., De Jager, C., Esiri, M. M., \& Chance, S. A. (2012, October). Prefrontal cortex cytoarchitecture in normal aging and Alzheimer's disease: A relationship with IQ. Brain Structure \& Function, 217(4), 797-808. PubMed https://doi.org/10.1007/s00429-012-0381-x

7. Hanseeuw, B. J., Betensky, R. A., Jacobs, H. I. L., Schultz, A. P., Sepulcre, J., Becker, J. A., . . . Johnson, K. (2019, August 1). Association of amyloid and tau with cognition in preclinical Alzheimer disease: A longitudinal study. JAMA Neurology, 76(8), 915-924. $\underline{\text { PubMed https://doi.org/10.1001/jamaneurol.2019.1424 }}$ 
8. Jansen, W. J., Ossenkoppele, R., Knol, D. L., Tijms, B. M., Scheltens, P., Verhey, F. R. J., . . .. Zetterberg, H., \& the Amyloid Biomarker Study Group. (2015, May 19). Prevalence of cerebral amyloid pathology in persons without dementia: A meta-analysis. JAMA, 313(19), 1924-1938. PubMed

9. Palmqvist, S., Janelidze, S., Quiroz, Y. T., Zetterberg, H., Lopera, F., Stomrud, E., . . . Hansson, O. (2020, August 25). Discriminative accuracy of plasma phospho-tau 217 for Alzheimer Disease vs other neurodegenerative disorders. JAMA, 324(8), 772-781. PubMed https://doi.org/10.1001/jama.2020.12134

10. Landhuis, E. (2021). Detecting Alzheimer's gets easier with a simple blood test. Scientific American, 3(1). Retrieved from https://www.scientificamerican.com/article/detectingalzheimers-gets-easier-with-a-simple-blood-test/

11. Fandos, N., Pérez-Grijalba, V., Pesini, P., Olmos, S., Bossa, M., Villemagne, V. L., .... Sarasa, M., \& the AIBL Research Group. (2017, September 12). Plasma amyloid $\beta$ 42/40 ratios as biomarkers for amyloid $\beta$ cerebral deposition in cognitively normal individuals. Alzheimers Dement (Amst), 8, 179-187. PubMed

12. Janelidze, S., Mattsson, N., Palmqvist, S., Smith, R., Beach, T. G., Serrano, G. E., . . . Hansson, O. (2020, March). Plasma P-tau181 in Alzheimer's disease: Relationship to other biomarkers, differential diagnosis, neuropathology and longitudinal progression to Alzheimer's dementia. Nature Medicine, 26(3), 379-386. PubMed https://doi.org/10.1038/s41591-020-0755-1

13. Alzheimer Europe. (2014). Value of Knowing. Retrieved from: https://www.alzheimereurope.org/Research/Value-of-Knowing

14. Erlangsen, A., Zarit, S. H., \& Conwell, Y. (2008, March). Hospital-diagnosed dementia and suicide: A longitudinal study using prospective, nationwide register data. Am J Geriatr Psychiatry, 16(3), 220-228. PubMed https://doi.org/10.1097/01.JGP.0000302930.75387.7e

15. Joe, E., \& Ringman, J. M. (2019, December 6). Cognitive symptoms of Alzheimer's disease: Clinical management and prevention. BMJ (Clinical Research Ed.), 367, 16217. PubMed https://doi.org/10.1136/bmj.16217

16. Masterman, D. (2004, February). Cholinesterase inhibitors in the treatment of Alzheimer's disease and related dementias. Clinics in Geriatric Medicine, 20(1), 59-68. PubMed https://doi.org/10.1016/j.cger.2003.11.002

17. Albert, M. S., DeKosky, S. T., Dickson, D., Dubois, B., Feldman, H. H., Fox, N. C., .. . Phelps, C. H. (2011, May). The diagnosis of mild cognitive impairment due to Alzheimer's disease: Recommendations from the National Institute on Aging-Alzheimer's Association workgroups on diagnostic guidelines for Alzheimer's disease. Alzheimers Dement, 7(3), 270-279. PubMed https://doi.org/10.1016/j.jalz.2011.03.008

18. Ritchie, C. W., \& Zhinchin, G. (2013, April). Low dose, high dose, or no dose: Better prescribing of cholinesterase inhibitors for Alzheimer's disease. International Psychogeriatrics, 25(4), 511-515. PubMed https://doi.org/10.1017/S1041610212002414

19. Chu, L. W. (2012, June). Alzheimer's disease: Early diagnosis and treatment. Hong Kong Med J, 18(3), 228-237. PubMed 
20. Birks, J. S., \& Harvey, R. J. (2018, June 18). Donepezil for dementia due to Alzheimer's disease. Cochrane Database Syst Rev, 6(6), CD001190. PubMed https://doi.org/10.1002/14651858.CD001190.pub3

21. Hansen, R. A., Gartlehner, G., Webb, A. P., Morgan, L. C., Moore, C. G., \& Jonas, D. E. (2008). Efficacy and safety of donepezil, galantamine, and rivastigmine for the treatment of Alzheimer's disease: A systematic review and meta-analysis. Clinical Interventions in Aging, 3(2), 211-225. PubMed

22. Breijyeh, Z., \& Karaman, R. (2020, December 8). Comprehensive review on Alzheimer's Disease: Causes and treatment. Molecules (Basel, Switzerland), 25(24), 5789. PubMed https://doi.org/10.3390/molecules25245789

23. Khoury, R., Rajamanickam, J., \& Grossberg, G. T. (2018, March). An update on the safety of current therapies for Alzheimer's disease: Focus on rivastigmine. Therapeutic Advances in Drug Safety, 9(3), 171-178. PubMed https://doi.org/10.1177/2042098617750555

24. Loy, C., \& Schneider, L. (2006, January 25). Galantamine for Alzheimer's disease and mild cognitive impairment. Cochrane Database Systemat Rev, (1): CD001747. PubMed https://doi.org/10.1002/14651858.CD001747.pub3

25. Sucher, N. J., Awobuluyi, M., Choi, Y. B., \& Lipton, S. A. (1996, October). NMDA receptors: From genes to channels. Trends in Pharmacological Sciences, 17(10), 348-355. PubMed https://doi.org/10.1016/S0165-6147(96)80008-3

26. Johnson, J. W., \& Kotermanski, S. E. (2006, February). Mechanism of action of memantine. Current Opinion in Pharmacology, 6(1), 61-67. PubMed https://doi.org/10.1016/j.coph.2005.09.007

27. Wang, R., \& Reddy, P. H. (2017). Role of glutamate and NMDA receptors in Alzheimer's Disease. J Alzheimers Dis, 57(4), 1041-1048. PubMed https://doi.org/10.3233/JAD-160763

28. Liu, J., Chang, L., Song, Y., Li, H., \& Wu, Y. (2019, February 8). The role of NMDA receptors in Alzheimer's Disease. Frontiers in Neuroscience, 13, 43. PubMed https://doi.org/10.3389/fnins.2019.00043

29. Reisberg, B., Doody, R., Stöffler, A., Schmitt, F., Ferris, S., \& Möbius, H. J., \& the Memantine Study Group. (2003, April 3). Memantine in moderate-to-severe Alzheimer's disease. The New England Journal of Medicine, 348(14), 1333-1341. PubMed https://doi.org/10.1056/NEJMoa013128

30. Matsunaga, S., Kishi, T., \& Iwata, N. (2015, April 10). Memantine monotherapy for Alzheimer's disease: A systematic review and meta-analysis. PLoS One, 10(4), e0123289. PubMed https://doi.org/10.1371/journal.pone.0123289

31. McShane, R., Westby, M. J., Roberts, E., Minakaran, N., Schneider, L., Farrimond, L. E., . . . Debarros, J. (2019, March 20). Memantine for dementia. Cochrane Database Syst Rev, 3(3), CD003154. PubMed

32. Kishi, T., Matsunaga, S., \& Iwata, N. (2017, July 20). The effects of memantine on behavioral disturbances in patients with Alzheimer's disease: A meta-analysis. Neuropsychiatric Disease and Treatment, 13, 1909-1928. PubMed https://doi.org/10.2147/NDT.S142839 
33. Atri, A., Hendrix, S. B., Pejović, V., Hofbauer, R. K., Edwards, J., Molinuevo, J. L., \& Graham, S. M. (2015, May 18). Cumulative, additive benefits of memantine-donepezil combination over component monotherapies in moderate to severe Alzheimer's dementia: A pooled area under the curve analysis. Alzheimer's Research \& Therapy, 7(1), 28. PubMed https://doi.org/10.1186/s13195-015-0109-2

34. Bakota, L., \& Brandt, R. (2016, March). Tau biology and tau-directed therapies for Alzheimer's Disease. Drugs, 76(3), 301-313. PubMed https://doi.org/10.1007/s40265-015$\underline{0529-0}$

35. Jia, Q., Deng, Y., \& Qing, H. (2014). Potential therapeutic strategies for Alzheimer's disease targeting or beyond $\beta$-amyloid: Insights from clinical trials. BioMed Research International, 2014, 1. PubMed

36. Nelson, P. T., Alafuzoff, I., Bigio, E. H., Bouras, C., Braak, H., Cairns, N. J., . . Beach, T. G. (2012, May). Correlation of Alzheimer disease neuropathologic changes with cognitive status: A review of the literature. Journal of Neuropathology and Experimental Neurology, 71(5), 362-381. PubMed https://doi.org/10.1097/NEN.0b013e31825018f7

37. Bejanin, A., Schonhaut, D. R., La Joie, R., Kramer, J. H., Baker, S. L., Sosa, N., . . . Rabinovici, G. D. (2017, December 1). Tau pathology and neurodegeneration contribute to cognitive impairment in Alzheimer's disease. Brain, 140(12), 3286-3300. PubMed https://doi.org/10.1093/brain/awx243

38. Gouras, G. K., Olsson, T. T., \& Hansson, O. (2015, January). $\beta$-Amyloid peptides and amyloid plaques in Alzheimer's disease. Neurotherapeutics, 12(1), 3-11. PubMed https://doi.org/10.1007/s13311-014-0313-y

39. Buchhave, P., Minthon, L., Zetterberg, H., Wallin, A. K., Blennow, K., \& Hansson, O. (2012, January). Cerebrospinal fluid levels of $\beta$-amyloid 1-42, but not of tau, are fully changed already 5 to 10 years before the onset of Alzheimer dementia. Archives of General Psychiatry, 69(1), 98-106. PubMed https://doi.org/10.1001/archgenpsychiatry.2011.155

40. Ricciarelli, R., \& Fedele, E. (2017). The amyloid cascade hypothesis in Alzheimer's Disease: It's time to change our mind. Current Neuropharmacology, 15(6), 926-935. PubMed https://doi.org/10.2174/1570159X15666170116143743

41. Panza, F., Lozupone, M., Solfrizzi, V., Sardone, R., Piccininni, C., Dibello, V., . . . Imbimbo, B. P. (2018, November). BACE inhibitors in clinical development for the treatment of Alzheimer's disease. Expert Review of Neurotherapeutics, 18(11), 847-857. PubMed https://doi.org/10.1080/14737175.2018.1531706

42. Panza, F., Lozupone, M., Seripa, D., \& Imbimbo, B. P. (2019, March). Amyloid- $\beta$ immunotherapy for alzheimer disease: Is it now a long shot? Annals of Neurology, 85(3), 303-315. PubMed https://doi.org/10.1002/ana.25410

43. Lozupone, M., Solfrizzi, V., D’Urso, F., Di Gioia, I., Sardone, R., Dibello, V., . . . Panza, F. (2020, September). Anti-amyloid- $\beta$ protein agents for the treatment of Alzheimer's disease: An update on emerging drugs. Expert Opinion on Emerging Drugs, 25(3), 319-335. PubMed https://doi.org/10.1080/14728214.2020.1808621 
44. Selkoe, D. J., \& Hardy, J. (2016, June 1). The amyloid hypothesis of Alzheimer's disease at 25 years. EMBO Molecular Medicine, 8(6), 595-608. PubMed https://doi.org/10.15252/emmm.201606210

45. Sevigny, J., Chiao, P., Bussière, T., Weinreb, P. H., Williams, L., Maier, M., ... Sandrock, A. (2016, September 1). The antibody aducanumab reduces A $\beta$ plaques in Alzheimer's disease. Nature, 537(7618), 50-56. PubMed https://doi.org/10.1038/nature19323

46. Loera-Valencia, R., Cedazo-Minguez, A., Kenigsberg, P. A., Page, G., Duarte, A. I., Giusti, P., ... Winblad, B. (2019, October). Current and emerging avenues for Alzheimer's disease drug targets. Journal of Internal Medicine, 286(4), 398-437. PubMed https://doi.org/10.1111/joim.12959

47. Mintun, M. A., Lo, A. C., Duggan Evans, C., Wessels, A. M., Ardayfio, P. A., Andersen, S. W., ... Skovronsky, D. M. (2021, May 6). Donanemab in Early Alzheimer's Disease. The New England Journal of Medicine, 384(18), 1691-1704. PubMed https://doi.org/10.1056/NEJMoa2100708

48. Lowe, S. L., Willis, B. A., Hawdon, A., Natanegara, F., Chua, L., Foster, J., . . Sims, J. R. (2021, February 14). Donanemab (LY3002813) dose-escalation study in Alzheimer's disease. Alzheimers Dement (NY), 7(1), e12112. PubMed https://doi.org/10.1002/trc2.12112

49. Bohrmann, B., Baumann, K., Benz, J., Gerber, F., Huber, W., Knoflach, F., .. . Loetscher, H. (2012). Gantenerumab: A novel human anti-A $\beta$ antibody demonstrates sustained cerebral amyloid- $\beta$ binding and elicits cell-mediated removal of human amyloid- $\beta$. J Alzheimers Dis, 28(1), 49-69. PubMed https://doi.org/10.3233/JAD-2011-110977

50. Ostrowitzki, S., Lasser, R. A., Dorflinger, E., Scheltens, P., Barkhof, F., Nikolcheva, T., . ... Fontoura, P., \& the SCarlet RoAD Investigators. (2017, December 8). A phase III randomized trial of gantenerumab in prodromal Alzheimer's disease. Alzheimer's Research \& Therapy, 9(1), 95. PubMed

51. Klein, G., Delmar, P., Voyle, N., Rehal, S., Hofmann, C., Abi-Saab, D., .. . Doody, R. (2019, December 12). Gantenerumab reduces amyloid- $\beta$ plaques in patients with prodromal to moderate Alzheimer's disease: A PET substudy interim analysis. Alzheimer's Research \& Therapy, 11(1), 101. PubMed https://doi.org/10.1186/s13195-019-0559-Z

52. Adolfsson, O., Pihlgren, M., Toni, N., Varisco, Y., Buccarello, A. L., Antoniello, K., ... Watts, R. J. (2012, July 11). An effector-reduced anti- $\beta$-amyloid (A $\beta$ ) antibody with unique a $\beta$ binding properties promotes neuroprotection and glial engulfment of A $\beta$. The Journal of Neuroscience : The Official Journal of the Society for Neuroscience, 32(28), 9677-9689. PubMed https://doi.org/10.1523/JNEUROSCI.4742-11.2012

53. Cummings, J. L., Cohen, S., van Dyck, C. H., Brody, M., Curtis, C., Cho, W., .. . Paul, R. (2018, May 22). ABBY: A phase 2 randomized trial of crenezumab in mild to moderate Alzheimer disease. Neurology, 90(21), e1889-e1897. PubMed https://doi.org/10.1212/WNL.0000000000005550

54. Imbimbo, B. P., \& Watling, M. (2019, November). Investigational BACE inhibitors for the treatment of Alzheimer's disease. Expert Opinion on Investigational Drugs, 28(11), 967975. PubMed https://doi.org/10.1080/13543784.2019.1683160 
55. Panza, F., Lozupone, M., Logroscino, G., \& Imbimbo, B. P. (2019, February). A critical appraisal of amyloid- $\beta$-targeting therapies for Alzheimer disease. Nature Reviews.

Neurology, 15(2), 73-88. PubMed https://doi.org/10.1038/s41582-018-0116-6

56. Vaz, M., \& Silvestre, S. (2020, November 15). Alzheimer's disease: Recent treatment strategies. European Journal of Pharmacology, 887, 173554. PubMed https://doi.org/10.1016/j.ejphar.2020.173554

57. Townsend, M., Cleary, J. P., Mehta, T., Hofmeister, J., Lesne, S., O’Hare, E., . . Selkoe, D. J. (2006, December). Orally available compound prevents deficits in memory caused by the Alzheimer amyloid-beta oligomers. Annals of Neurology, 60(6), 668-676. PubMed https://doi.org/10.1002/ana.21051

58. Rafii, M. S., Skotko, B. G., McDonough, M. E., Pulsifer, M., Evans, C., Doran, E., .... Lott, I. T., \& the ELND005-DS Study Group. (2017). A randomized, double-blind, placebocontrolled, phase ii study of oral ELND005 (scyllo-Inositol) in young adults with Down Syndrome without dementia. J Alzheimers Dis, 58(2), 401-411. PubMed

59. Salloway, S., Sperling, R., Keren, R., Porsteinsson, A. P., van Dyck, C. H., Tariot, P. N., . . .. Cedarbaum, J. M., \& the ELND005-AD201 Investigators. (2011, September 27). A phase 2 randomized trial of ELND005, scyllo-inositol, in mild to moderate Alzheimer disease. Neurology, 77(13), 1253-1262. PubMed

60. Hey, J. A., Yu, J. Y., Versavel, M., Abushakra, S., Kocis, P., Power, A., . . Tolar, M. (2018, March). Clinical pharmacokinetics and safety of ALZ-801, a novel prodrug of tramiprosate in development for the treatment of Alzheimer's Disease. Clinical Pharmacokinetics, 57(3), 315-333. PubMed https://doi.org/10.1007/s40262-017-0608-3

61. Tolar, M., Abushakra, S., Hey, J. A., Porsteinsson, A., \& Sabbagh, M. (2020, August 12). Aducanumab, gantenerumab, BAN2401, and ALZ-801-the first wave of amyloid-targeting drugs for Alzheimer's disease with potential for near term approval. Alzheimer's Research \& Therapy, 12(1), 95. PubMed https://doi.org/10.1186/s13195-020-00663-w

62. Abushakra, S., Porsteinsson, A., Scheltens, P., Sadowsky, C., Vellas, B., Cummings, J., .. . Tolar, M. (2017). Clinical effects of tramiprosate in APOE4/4 homozygous patients with mild Alzheimer's Disease suggest disease modification potential. The Journal of Prevention of Alzheimer's Disease, 4(3), 149-156. PubMed

63. Plotkin, S. S., \& Cashman, N. R. (2020, October). Passive immunotherapies targeting A $\beta$ and tau in Alzheimer's disease. Neurobiology of Disease, 144, 105010. PubMed https://doi.org/10.1016/j.nbd.2020.105010

64. Congdon, E. E., Wu, J. W., Myeku, N., Figueroa, Y. H., Herman, M., Marinec, P. S., . . Duff, K. E. (2012, April). Methylthioninium chloride (methylene blue) induces autophagy and attenuates tauopathy in vitro and in vivo. Autophagy, 8(4), 609-622. PubMed https://doi.org/10.4161/auto.19048

65. Tucker, D., Lu, Y., \& Zhang, Q. (2018, June). From mitochondrial function to neuroprotection-an emerging role for methylene blue. Molecular Neurobiology, 55(6), 5137-5153. PubMed https://doi.org/10.1007/s12035-017-0712-2

66. Medina, D. X., Caccamo, A., \& Oddo, S. (2011, March). Methylene blue reduces aß levels and rescues early cognitive deficit by increasing proteasome activity. Brain Pathology 
(Zurich, Switzerland), 21(2), 140-149. PubMed https://doi.org/10.1111/j.17503639.2010.00430.x

67. Wischik, C. M., Edwards, P. C., Lai, R. Y., Roth, M., \& Harrington, C. R. (1996, October 1). Selective inhibition of Alzheimer disease-like tau aggregation by phenothiazines.

Proceedings of the National Academy of Sciences of the United States of America, 93(20), 11213-11218. PubMed https://doi.org/10.1073/pnas.93.20.11213

68. Soeda, Y., Saito, M., Maeda, S., Ishida, K., Nakamura, A., Kojima, S., \& Takashima, A. (2019). Methylene blue inhibits formation of tau fibrils but not of granular tau oligomers: A plausible key to understanding failure of a clinical trial for Alzheimer's disease. $J$ Alzheimers Dis, 68(4), 1677-1686. PubMed https://doi.org/10.3233/JAD-181001

69. Hu, S., Maiti, P., Ma, Q., Zuo, X., Jones, M. R., Cole, G. M., \& Frautschy, S. A. (2015, June). Clinical development of curcumin in neurodegenerative disease. Expert Review of Neurotherapeutics, 15(6), 629-637. PubMed https://doi.org/10.1586/14737175.2015.1044981

70. Reddy, P. H., Manczak, M., Yin, X., Grady, M. C., Mitchell, A., Tonk, S., .. . Reddy, A. P. (2018). Protective effects of Indian spice curcumin against amyloid- $\beta$ in Alzheimer's disease. J Alzheimers Dis, 61(3), 843-866. PubMed https://doi.org/10.3233/JAD-170512

71. Shultz, S. R., Wright, D. K., Zheng, P., Stuchbery, R., Liu, S.-J., Sashindranath, M., . . . O'Brien, T. J. (2015, May). Sodium selenate reduces hyperphosphorylated tau and improves outcomes after traumatic brain injury. Brain, 138(5), 1297-1313. PubMed https://doi.org/10.1093/brain/awv053

72. Rueli, R. H., Torres, D. J., Dewing, A. S., Kiyohara, A. C., Barayuga, S. M., Bellinger, M. T., . . B Bellinger, F. P. (2016). Selenoprotein S reduces endoplasmic reticulum stressinduced phosphorylation of tau: Potential role in selenate mitigation of tau pathology. $J$ Alzheimers Dis, 55(2), 749-762. PubMed https://doi.org/10.3233/JAD-151208

73. Malpas, C. B., Vivash, L., Genc, S., Saling, M. M., Desmond, P., Steward, C., .. . O'Brien, T. J. (2016, July 22). A phase IIa randomized control trial of VEL015 (sodium selenate) in mild-moderate Alzheimer's disease. J Alzheimers Dis, 54(1), 223-232. PubMed https://doi.org/10.3233/JAD-160544

74. Cardoso, B. R., Roberts, B. R., Malpas, C. B., Vivash, L., Genc, S., Saling, M. M., ... Bush, A. I. (2019, January). Supranutritional sodium selenate supplementation delivers selenium to the central nervous system: Results from a randomized controlled pilot trial in Alzheimer's disease. Neurotherapeutics, 16(1), 192-202. PubMed https://doi.org/10.1007/s13311-018$\underline{0662-\mathrm{Z}}$

75. Congdon, E. E., \& Sigurdsson, E. M. (2018, July). Tau-targeting therapies for Alzheimer disease. Nature Reviews. Neurology, 14(7), 399-415. PubMed https://doi.org/10.1038/s41582-018-0013-z

76. Rao, C. V., Asch, A. S., Carr, D. J. J., \& Yamada, H. Y. (2020, March). "Amyloid-beta accumulation cycle" as a prevention and/or therapy target for Alzheimer's disease. Aging Cell, 19(3), e13109. PubMed https://doi.org/10.1111/acel.13109 
77. Wadhwa, P., Jain, P., \& Jadhav, H. R. (2020). Glycogen synthase kinase 3 (GSK3): Its role and inhibitors. Current Topics in Medicinal Chemistry, 20(17), 1522-1534. PubMed https://doi.org/10.2174/1568026620666200516153136

78. Lovestone, S., Boada, M., Dubois, B., Hüll, M., Rinne, J. O., Huppertz, H.-J., . . .. del Ser, T., \& the ARGO investigators. (2015). A phase II trial of tideglusib in Alzheimer's disease. $J$ Alzheimers Dis, 45(1), 75-88. PubMed

79. Matsunaga, S., Fujishiro, H., \& Takechi, H. (2019). Efficacy and safety of glycogen synthase kinase 3 inhibitors for Alzheimer's disease: A systematic review and metaanalysis. J Alzheimers Dis, 69(4), 1031-1039. PubMed https://doi.org/10.3233/JAD-190256

80. Butler, D., Bendiske, J., Michaelis, M. L., Karanian, D. A., \& Bahr, B. A. (2007, May 7). Microtubule-stabilizing agent prevents protein accumulation-induced loss of synaptic markers. European Journal of Pharmacology, 562(1-2), 20-27. PubMed https://doi.org/10.1016/j.ejphar.2007.01.053

81. Tsai, R. M., Miller, Z., Koestler, M., Rojas, J. C., Ljubenkov, P. A., Rosen, H. J., . . Boxer, A. L. (2020, February 1). Reactions to multiple ascending doses of the microtubule stabilizer tpi-287 in patients with Alzheimer disease, progressive supranuclear palsy, and corticobasal syndrome: A randomized clinical trial. JAMA Neurology, 77(2), 215-224. PubMed https://doi.org/10.1001/jamaneurol.2019.3812

82. Zhang, J., Wei, S. Y., Yuan, L., Kong, L. L., Zhang, S. X., Wang, Z. J., . . Qi, J. S. (2017, May 15). Davunetide improves spatial learning and memory in Alzheimer's diseaseassociated rats. Physiology \& Behavior, 174, 67-73. PubMed https://doi.org/10.1016/j.physbeh.2017.02.038

83. Matsuoka, Y., Jouroukhin, Y., Gray, A. J., Ma, L., Hirata-Fukae, C., Li, H. F., . . Aisen, P. S. (2008, April). A neuronal microtubule-interacting agent, NAPVSIPQ, reduces tau pathology and enhances cognitive function in a mouse model of Alzheimer's disease. The Journal of Pharmacology and Experimental Therapeutics, 325(1), 146-153. PubMed https://doi.org/10.1124/jpet.107.130526

84. Morimoto, B. H., Schmechel, D., Hirman, J., Blackwell, A., Keith, J., \& Gold, M., \& the AL-108-211 Study. (2013). A double-blind, placebo-controlled, ascending-dose, randomized study to evaluate the safety, tolerability and effects on cognition of AL-108 after 12 weeks of intranasal administration in subjects with mild cognitive impairment. Dementia and Geriatric Cognitive Disorders, 35(5-6), 325-339. PubMed

85. Novak, P., Schmidt, R., Kontsekova, E., Zilka, N., Kovacech, B., Skrabana, R., .. . Novak, M. (2017, February). Safety and immunogenicity of the tau vaccine AADvac1 in patients with Alzheimer's disease: A randomised, double-blind, placebo-controlled, phase 1 trial. Lancet Neurol, 16(2), 123-134. PubMed https://doi.org/10.1016/S1474-4422(16)30331-3

86. Novak, P., Schmidt, R., Kontsekova, E., Kovacech, B., Smolek, T., Katina, S., . . Novak, M. (2018, October 24). FUNDAMANT: An interventional 72-week phase 1 follow-up study of AADvac1, an active immunotherapy against tau protein pathology in Alzheimer's disease. Alzheimer's Research \& Therapy, 10(1), 108. PubMed https://doi.org/10.1186/s13195-018-0436-1 
87. Panza, F., Solfrizzi, V., Seripa, D., Imbimbo, B. P., Lozupone, M., Santamato, A., . . . Logroscino, G. (2016, September). Tau-based therapeutics for Alzheimer's disease: Active and passive immunotherapy. Immunotherapy, 8(9), 1119-1134. PubMed https://doi.org/10.2217/imt-2016-0019

88. Theunis, C., Crespo-Biel, N., Gafner, V., Pihlgren, M., López-Deber, M. P., Reis, P., . . . Muhs, A. (2013, August 19). Efficacy and safety of a liposome-based vaccine against protein Tau, assessed in tau.P301L mice that model tauopathy. PLoS One, 8(8), e 72301. PubMed https://doi.org/10.1371/journal.pone.0072301

89. Gu, J., Congdon, E. E., \& Sigurdsson, E. M. (2013, November 15). Two novel Tau antibodies targeting the 396/404 region are primarily taken up by neurons and reduce Tau protein pathology. The Journal of Biological Chemistry, 288(46), 33081-33095. PubMed https://doi.org/10.1074/jbc.M113.494922

90. Congdon, E. E., Gu, J., Sait, H. B., \& Sigurdsson, E. M. (2013, December 6). Antibody uptake into neurons occurs primarily via clathrin-dependent Fc $\gamma$ receptor endocytosis and is a prerequisite for acute tau protein clearance. The Journal of Biological Chemistry, 288(49), 35452-35465. PubMed https://doi.org/10.1074/jbc.M113.491001

91. McEwan, W. A., Falcon, B., Vaysburd, M., Clift, D., Oblak, A. L., Ghetti, B., . . James, L. C. (2017, January 17). Cytosolic Fc receptor TRIM21 inhibits seeded tau aggregation. Proceedings of the National Academy of Sciences of the United States of America, 114(3), 574-579. PubMed https://doi.org/10.1073/pnas.1607215114

92. Hoskin, J. L., Sabbagh, M. N., Al-Hasan, Y., \& Decourt, B. (2019, June). Tau immunotherapies for Alzheimer's disease. Expert Opinion on Investigational Drugs, 28(6), 545-554. PubMed https://doi.org/10.1080/13543784.2019.1619694

93. Boxer, A. L., Qureshi, I., Ahlijanian, M., Grundman, M., Golbe, L. I., Litvan, I., .. . Dam, T. (2019, June). Safety of the tau-directed monoclonal antibody BIIB092 in progressive supranuclear palsy: A randomised, placebo-controlled, multiple ascending dose phase $1 \mathrm{~b}$ trial. Lancet Neurol, 18(6), 549-558. PubMed https://doi.org/10.1016/S14744422(19)30139-5

94. Dage, J. L., Wennberg, A. M. V., Airey, D. C., Hagen, C. E., Knopman, D. S., Machulda, M. M., . . Mielke, M. M. (2016, December). Levels of tau protein in plasma are associated with neurodegeneration and cognitive function in a population-based elderly cohort. Alzheimers Dement, 12(12), 1226-1234. PubMed https://doi.org/10.1016/j.jalz.2016.06.001

95. Ayalon, G., Lee, S. H., Adolfsson, O., Foo-Atkins, C., Atwal, J. K., Blendstrup, M., .. . Kerchner, G. A. (2021, May 12). Antibody semorinemab reduces tau pathology in a transgenic mouse model and engages tau in patients with Alzheimer's disease. Science Translational Medicine, 13(593), eabb2639. PubMed https://doi.org/10.1126/scitranslmed.abb2639

96. Kerchner, G. A., Ayalon, G., Blendstrup, M., Brunstein, F., Chandra, P., Datwani, A., . . Foo-Atkins, C. (2017). Targeting tau with RO7105705: Phase I results and design of a phase II study in prodromal-mild AD. The Journal of Prevention of Alzheimer's Disease, 4(4), 312-313. 
97. Fernández, M., Gobartt, A. L., \& Balañá, M., \& the COOPERA Study Group. (2010, September 28). Behavioural symptoms in patients with Alzheimer's disease and their association with cognitive impairment. BMC Neurology, 10, 87. PubMed https://doi.org/10.1186/1471-2377-10-87

98. Vik-Mo, A. O., Giil, L. M., Borda, M. G., Ballard, C., \& Aarsland, D. (2020, January). The individual course of neuropsychiatric symptoms in people with Alzheimer's and Lewy body dementia: 12-year longitudinal cohort study. Br J Psychiatry, 216(1), 43-48. PubMed https://doi.org/10.1192/bjp.2019.195

99. Magierski, R., Sobow, T., Schwertner, E., \& Religa, D. (2020, July 31). Pharmacotherapy of behavioral and psychological symptoms of dementia: State of the art and future progress. Frontiers in Pharmacology, 11, 1168. PubMed https://doi.org/10.3389/fphar.2020.01168

100. Schneider, L. S., Dagerman, K. S., \& Insel, P. (2005, October 19). Risk of death with atypical antipsychotic drug treatment for dementia: Meta-analysis of randomized placebocontrolled trials. JAMA, 294(15), 1934-1943. PubMed https://doi.org/10.1001/jama.294.15.1934

101.Maust, D. T., Kim, H. M., Seyfried, L. S., Chiang, C., Kavanagh, J., Schneider, L. S., \& Kales, H. C. (2015, May). Antipsychotics, other psychotropics, and the risk of death in patients with dementia: Number needed to harm. JAMA Psychiatry, 72(5), 438-445. PubMed https://doi.org/10.1001/jamapsychiatry.2014.3018

102.Reus, V. I., Fochtmann, L. J., Eyler, A. E., Hilty, D. M., Horvitz-Lennon, M., Jibson, M. D., ... Yager, J. (2016, May 1). The American Psychiatric Association practice guideline on the use of antipsychotics to treat agitation or psychosis in patients with dementia. The American Journal of Psychiatry, 173(5), 543-546. PubMed https://doi.org/10.1176/appi.ajp.2015.173501

103. Yunusa, I., Alsumali, A., Garba, A. E., Regestein, Q. R., \& Eguale, T. (2019, March 1). Assessment of reported comparative effectiveness and safety of atypical antipsychotics in the treatment of behavioral and psychological symptoms of dementia: A network metaanalysis. JAMA Network Open, 2(3), e190828. PubMed https://doi.org/10.1001/jamanetworkopen.2019.0828

104.Pollock, B. G., Mulsant, B. H., Sweet, R., Burgio, L. D., Kirshner, M. A., Shuster, K., \& Rosen, J. (1997, Winter). An open pilot study of citalopram for behavioral disturbances of dementia. Plasma levels and real-time observations. Am J Geriatr Psychiatry, 5(1), 70-78. PubMed https://doi.org/10.1097/00019442-199705010-00009

105.Porsteinsson, A. P., Drye, L. T., Pollock, B. G., Devanand, D. P., Frangakis, C., Ismail, Z., . ... Lyketsos, C. G., \& the CitAD Research Group. (2014, February 19). Effect of citalopram on agitation in Alzheimer disease: The CitAD randomized clinical trial. JAMA, 311(7), 682691. PubMed

106.Drye, L. T., Spragg, D., Devanand, D. P., Frangakis, C., Marano, C., Meinert, C. L., . ... Lyketsos, C. G., \& the CitAD Research Group. (2014, June 10). Changes in QTc interval in the citalopram for agitation in Alzheimer's disease (CitAD) randomized trial. PLoS One, 9(6), e98426. PubMed 
107. Weintraub, D., Drye, L. T., Porsteinsson, A. P., Rosenberg, P. B., Pollock, B. G., Devanand, D. P., .... Lyketsos, C. G., \& the CitAD Research Group. (2015, November). Time to response to citalopram treatment for agitation in Alzheimer Disease. Am J Geriatr Psychiatry, 23(11), 1127-1133. PubMed

108.Seitz, D. P., Adunuri, N., Gill, S. S., Gruneir, A., Herrmann, N., \& Rochon, P. (2011, February 16). Antidepressants for agitation and psychosis in dementia. Cochrane Database Syst Rev, (2): CD008191. PubMed https://doi.org/10.1002/14651858.CD008191.pub2

109. Aga, V. M. (2019, October). When and how to treat agitation in Alzheimer's disease dementia with citalopram and escitalopram. Am J Geriatr Psychiatry, 27(10), 1099-1107. PubMed https://doi.org/10.1016/j.jagp.2019.04.016

110.Kamei, H., Kameyama, T., \& Nabeshima, T. (1996, March 28). (+)-SKF-10,047 and dextromethorphan ameliorate conditioned fear stress through the activation of phenytoinregulated sigma 1 sites. European Journal of Pharmacology, 299(1-3), 21-28. PubMed https://doi.org/10.1016/0014-2999(95)00830-6

111. Marcinkowska, M., Śniecikowska, J., Fajkis, N., Paśko, P., Franczyk, W., \& Kołaczkowski, M. (2020, March). Management of dementia-related psychosis, agitation and aggression: A review of the pharmacology and clinical effects of potential drug candidates. CNS Drugs, 34(3), 243-268. PubMed https://doi.org/10.1007/s40263-020-00707-7

112.Garay, R. P., \& Grossberg, G. T. (2017, January). AVP-786 for the treatment of agitation in dementia of the Alzheimer's type. Expert Opinion on Investigational Drugs, 26(1), 121132. PubMed https://doi.org/10.1080/13543784.2017.1267726

113. Khoury, R., Marx, C., Mirgati, S., Velury, D., Chakkamparambil, B., \& Grossberg, G. T. (2021, May). AVP-786 as a promising treatment option for Alzheimer's Disease including agitation. Expert Opinion on Pharmacotherapy, 22(7), 783-795. PubMed https://doi.org/10.1080/14656566.2021.1882995

114.Cummings, J. (2021, January 13). New approaches to symptomatic treatments for Alzheimer's disease. Molecular Neurodegeneration, 16(1), 2. PubMed https://doi.org/10.1186/s13024-021-00424-9

115.Liu, C. S., Chau, S. A., Ruthirakuhan, M., Lanctôt, K. L., \& Herrmann, N. (2015, August). Cannabinoids for the treatment of agitation and aggression in Alzheimer's Disease. CNS Drugs, 29(8), 615-623. PubMed https://doi.org/10.1007/s40263-015-0270-y

116.Herrmann, N., Ruthirakuhan, M., Gallagher, D., Verhoeff, N. P. L. G., Kiss, A., Black, S. E., \& Lanctôt, K. L. (2019, November). Randomized placebo-controlled trial of nabilone for agitation in Alzheimer's Disease. Am J Geriatr Psychiatry, 27(11), 1161-1173. PubMed https://doi.org/10.1016/j.jagp.2019.05.002

117.Hillen, J. B., Soulsby, N., Alderman, C., \& Caughey, G. E. (2019, May 15). Safety and effectiveness of cannabinoids for the treatment of neuropsychiatric symptoms in dementia: A systematic review. Therapeutic Advances in Drug Safety, 10, 2042098619846993. PubMed https://doi.org/10.1177/2042098619846993

118.Paunescu, H., Dima, L., Ghita, I., Coman, L., Ifteni, P. I., Fulga, I., \& Coman, O. A. (2020, May/June). A systematic review of clinical studies on the effect of psychoactive 
cannabinoids in psychiatric conditions in Alzheimer Dementia. American Journal of Therapeutics, 27(3), e249-e269. PubMed https://doi.org/10.1097/MJT.0000000000001120

119. Ruthirakuhan, M., Lanctôt, K. L., Vieira, D., \& Herrmann, N. (2019, January 29). Natural and synthetic cannabinoids for agitation and aggression in Alzheimer's Disease: A metaanalysis. Can J Psychiatry, 80(2), 18r12617. PubMed

120.Bahji, A., Meyyappan, A. C., \& Hawken, E. R. (2020, June). Cannabinoids for the neuropsychiatric symptoms of dementia: A systematic review and meta-analysis. Canadian Journal of Psychiatry, 65(6), 365-376. PubMed https://doi.org/10.1177/0706743719892717

121.Caraci, F., Santagati, M., Caruso, G., Cannavò, D., Leggio, G. M., Salomone, S., \& Drago, F. (2020, July 8). New antipsychotic drugs for the treatment of agitation and psychosis in Alzheimer's disease: Focus on brexpiprazole and pimavanserin. F1000Res, 9, 686. PubMed https://doi.org/10.12688/f1000research.22662.1

122.Grossberg, G. T., Kohegyi, E., Mergel, V., Josiassen, M. K., Meulien, D., Hobart, M., . . . Cummings, J. L. (2020, April). Efficacy and safety of brexpiprazole for the treatment of agitation in Alzheimer's Dementia: Two 12-week, randomized, double-blind, placebocontrolled trials. Am J Geriatr Psychiatry, 28(4), 383-400. PubMed https://doi.org/10.1016/j.jagp.2019.09.009

123. Wang, L. Y., Shofer, J. B., Rohde, K., Hart, K. L., Hoff, D. J., McFall, Y. H., . . Peskind, E. R. (2009, September). Prazosin for the treatment of behavioral symptoms in patients with Alzheimer disease with agitation and aggression. Am J Geriatr Psychiatry, 17(9), 744-751. PubMed https://doi.org/10.1097/JGP.0b013e3181ab8c61

124. Williams, S. M., Chapman, D., \& Lando, J., \& the Centers for Disease Control and Prevention (CDC). (2005, September 2). The role of public health in mental health promotion. MMWR. Morbidity and Mortality Weekly Report, 54(34), 841-842. PubMed

125.Herman, C. (2006, January 1). What makes a screening exam "good"? Virtual Mentor, 8(1), 34-37. PubMed

Copyright (c) 2021 Delaware Academy of Medicine / Delaware Public Health Association.

This is an Open Access article distributed under the terms of the Creative Commons Attribution Non-Commercial License (https://creativecommons.org/licenses/by-nc-nd/4.0/) which permits unrestricted non-commercial use, distribution, and reproduction in any medium, provided the original work is properly cited. 